\title{
An Overview Of Selected Errors \\ In The Written English Of Tamil Undergraduates \\ Sheena Kaur
}

\begin{abstract}
Absíracî
The findings described in this study are based on a preliminary analysis of errors produced in the writing of 30 Tamil undergraduates. This paper's concern is the examination and categorisation of errors found in the written English of native adult speakers of Tamil who are currently undergoing a Bachelor Degree in Language and Linguistics majoring in Tamil, at the Faculty of Languages and Linguistics, University of Malaya. This article will examine selectively, rather than exhaustively, some of the most frequently recurring errors in grammar, spelling and lexis found in the data. It is hoped that the present study will cast some light on some of the common weaknesses with which students need help, which will be helpful to the classroom teacher dealing with learners of similar linguistic background.
\end{abstract}

\subsection{Introduction}

The study of language errors made by learners in the process of learning a second language has always been the interest of linguists and language instructors. Since the 1940s and up to the mid-1960s, errors were considered solely the products of native language habits. Language errors were believed to be the result of established native language habits interfering with the learning of the second language (Lado 1957; Politzer 1965; Di Pietro 1971). This approach formed the basis of the Contrastive Analysis Hypothesis (CA). Proponents of CA contended that the learning problems common to second language learners could be predicted by comparing the $\mathrm{L} 1$ and $\mathrm{L} 2$ systems. It was thought that the greater the difference between the linguistic structures of L1 and L2 in terms of phonology, morphology and syntax, the more complex would the learning difficulties be for the L2 learner, and vice versa. This is the notion underlying the strong version of $\mathrm{CA}$, which has been severely criticized on the basis of its theoretical assumptions and predictive validity (Banathy and Madarasz 1969; Nickel 1971; Wardhaugh 1983; Cook 1993). 
Researchers working with actual errors produced by learners found that many errors predicted by CA did not turn out to be genuine problems for the learners, and that many of the actual problems had not been predicted at all. The linguistic difference between the $\mathrm{L} 1$ and L2 did not in fact equal to L2 learning difficulty. Other common findings revealed that a majority of L2 errors were not traceable to L1, but were the result of complexities within the L2 itself, as well as general linguistic strategies observable both in the first and the second language learner (Corder 1967; Selinker 1969; Richards 1974; James 1998).

A gradual shift of interest in the late 1960s led to the study of actual errors produced by L2 learners, which was believed to provide a better understanding into the process of $\mathrm{L} 2$ learning. This resulted in the Error Analysis Hypothesis (EA) which involved collecting, analysing and categorising L2 errors systematically in order to account for the different levels of difficulties and the sources of errors (Corder 1967). Errors made by second language learners were found to be not a result of total interference of native language habits, but rather evidence of an underlying rule-governed system the learner had of his second language. Corder (1967), who regards errors as inevitable, and the process of making errors as a device the learner uses in order to learn, best summarizes learner errors as those that "provide evidence of the system of the language that he is using (i.e., has learned) at a particular point in the course (and it must be repeated that he is using some system, although it is not yet the right system)" (Corder 1967:166).

Errors have come to be regarded by linguists as evidence of the learner's strategy and the route he follows when building up competence in the second language (Richards 1974; Corder 1981; Gass and Selinker 1993; James 1998). Error analysis studies also provide evidence of similarity of the learning processes between $\mathrm{L} 1$ and $\mathrm{L} 2$; and find that irrespective of the native language, second language learner data reflect errors that are very much like those children make as they learn a first language (Ravem 1968; Cook 1973; Dulay, Burt and Krashen 1982; Larsen-Freeman and Long 1991).

Error analysis studies have suggested several sources of errors. Explanation of the errors, however, is largely speculative by nature and it is difficult to pinpoint the exact source of error. This is mainly due to the fact that several reasons may be responsible for an error. Linguistic studies reveal that $\mathrm{L} 2$ errors can be traced to two main sources, namely interlingual and intralingual errors. Interlingual errors are errors that originate from the transfer of linguistic structures from the learner's L1 to his $\mathrm{L} 2$. Both positive and negative transfer can occur. The percentage of errors traceable to $\mathrm{L} 1$ interference are generally reported to be small. George (1972) claims that one-third of deviant structures from L2 learners are attributable 
to language transfer. Dulay and Burt (1974) contend that less than 5\% of errors in English made by Spanish-speaking children are caused by interference, while up to $87 \%$ are caused by developmental strategies and the remaining approximately $8 \%$ are ambiguous errors which do not reflect either the first or the second language structure.

Errors are also traceable to confusion between forms and functions of the language being learned. These are known as intralingual errors, which are errors that originate from the second language itself based on generalisations made by the learner. Intralingual errors represent the typical kind of errors produced by a learner irrespective of his L1. Richards (1974) found that in a study of English errors produced by speakers of Japanese, Chinese, Burmese, French, Czech, Polish, Tagalog, Maori and Maltese, the error patterns were not solely due to the interference from the native language but due to what he calls overgeneralisations, ignorance of rule restrictions, incomplete application of rules and hypothesizing false concepts about the target language.

The role of EA in language teaching and learning cannot be denied, especially and this is especially so for the language teacher. Errors provide feedback to the teacher about the effectiveness of the teaching material and techniques, as well as how much the learner has internalized. It is believed that a teacher's familiarity with the learner's errors will be a valuable guide to determine the sequence of language instruction specifically geared towards addressing the linguistic difficulties of the learners. A study of learner errors helps the teacher assess more accurately what remedial work will be necessary in order to eradicate the most common errors that keep recurring. In justifying the study of learner errors, Corder (1973) claims that errors are also significant to the researcher and the learner himself. The researcher is able to gauge the kinds of strategies the learner employs in learning the language. Meanwhile, the learner, while attempting to correct errors, develops a strategy, which can be used to test and retest hypotheses about the linguistic structures of his target language.

The present study is thus an attempt, based on the investigation of written data, to identify and categorise the types of errors found in grammar, spelling and lexis made by a group of Tamil undergraduates. It is hoped that a study of such nature will provide valuable feedback to the English language teacher in the areas which pose difficulty to Tamil-speaking English language learners so that appropriate remedial measures can be adopted to help these students overcome the most common language errors. This study does not set out to investigate the sources of the errors, and hence the categorisation of errors is based on error types, rather than sources of errors. It is felt that an investigation into the sources of errors would 
form part of a separate analysis altogether and it is beyond the scope of this study.

\subsection{Subjects}

The subjects of the study comprise 30 out of 53 Tamil-speaking undergraduates of the Faculty of Languages and Linguistics. Thus, the sample represents more than half of the total population under study. The subjects are currently pursuing a degree in Language and Linguistics, majoring in Tamil, in the 2000/2001 academic year. The subjects consist of 12 males and 18 females, ranging from the ages of 21 to 44 , the average age being 30 . All but two of the subjects are college-trained teachers who have taken study leave from the Ministry of Education to upgrade themselves by pursuing a degree. The other two are fresh school leavers who have come in after Form Six. The teaching experience that these teachers have, ranges from 4 to 24 years, with the average being 11 years. All except five of them are teaching in Tamil primary schools. The other five are teaching in Lower Secondary Schools. Only five of the subjects said that they teach English in schools.

All 30 subjects completed their primary education under the Tamil medium of instruction at Tamil national type schools. 25 of the subjects received secondary school education at national schools where Bahasa Malaysia was the medium of instruction, while the other five attended English-medium national schools. All in all, the subjects had had not less than 10 successive years of formal instruction in English in school. At the university level, a majority of the subjects had done the GTEB Am (General English Proficiency Course) and GTEB Khas (English for Specific Purpose Course), each with 4 contact hours per week, offered by the university.

All of the subjects communicate mainly in Tamil in their homes and rarely speak English with others except with their English teachers. Most indicated using Malay to communicate with their non-Tamil friends and non-Tamil teachers. English is only used when the interlocutor cannot speak either Tamil or Malay. However, all the subjects expressed interest in studying English. The various reasons cited for this were the importance of English as an international language and the language of the internet and computers; as the language used in journal articles and reference books in English; as the language used to communicate with foreigners and as the language used in formal situations. Some of the subjects in the sample also felt that they needed English as society perceives a teacher, whatever the subject he teaches, to be fluent in English.

\subsection{Procedure}

The subjects were gathered in a classroom and were required to complete a written task 
within one hour. Subjects were also required to fill a questionnaire after that for the purpose of eliciting background information about them. The written task was to complete three paragraphs of approximately 8 to 10 sentences on each of the following:

1. My happiest moment in life was when...

2. My life as an undergraduate now is...

3. Next weekend,...

The rationale for the choice of topics was to enable the subjects to write without being constrained by the need for specialised vocabulary as the topics dealt with everyday life. The researcher had prior to this, conducted a pilot study in which a variety of topics were given to three other students to test the suitability of the task in gauging the kinds of errors produced. It was found that factual topics restricted the ability of the students to express themselves. Hence, the researcher decided upon topics which were descriptive and narrative in nature.

The writing task was then reviewed and corrected by the researcher, while retaining the language used by the students as much as possible. The writing task was also given to another lecturer to be corrected to obtain unanimity concerning the reliability of evaluation in terms of errors. Any discrepancies about what constituted an error were ironed out between the researcher and the inter-rater.

The researcher looked at errors which reveal the learner's underlying knowledge of the linguistic system of the English language. These errors are known as competence errors. The researcher did not look at mistakes which are unsystematic, occasional and occur typically at random. Mistakes, also known as performance errors, are deviations due to performance factors such as lapses of memory, fatigue and carelessness. Mistakes are commonly made by native as well as competent speakers of a language and can easily be eliminated by emphasis on accuracy and carefulness. In an error analysis research, mistakes are of no pedagogical relevance.

The errors in this study are classified under three main categories, namely, grammatical errors, spelling errors and lexical errors. The types of errors under each main category are established based on the characteristics of each error type. The error types are classified in terms of distributional occurrences rather than psycholinguistic causes. In drawing up a classification of error types, the researcher adapted the error taxonomies used by Corder (1973) and James (1998). 


\subsection{Resulits and Analysis of Data}

A total of 6069 words were produced from 30 scripts, of which the overall average length per script was 202 words. The total number of sentences produced was 519 and the average number of sentences written per student was approximately 17. Analysis of the compositions showed that of the total number of sentences produced, 405 or $78 \%$ were erroneous: they were either ungrammatical or inappropriate. The average erroneous sentence per student was 13.5 sentences. What was interesting to note here was that there was a remarkable discrepancy in the number of error-free sentences produced by the 5 subjects who had their secondary education in English medium schools as compared to the other 25 students who had their secondary education in the Malay medium. The subjects from the English medium schools produced four times more error-free sentences compared to subjects from the Malay medium schools. Of the total 84 sentences produced by the English medium students, 53 $(63 \%)$ were error-free. On the other hand, subjects from the Malay medium schools produced 61 (14\%) error-free sentences from a total of 435 sentences. The study, however, does not attempt to study the difference between the types of errors produced by both groups, but will look at the errors collectively.

The types and frequencies of errors are classified under three main categories (grammatical errors, spelling errors and lexical errors). Table 1 shows the distribution of the frequency of errors and the percentage of errors under each category. The error count is presented in terms of its statistical significance by matching it against the total number of occurence of error in each category.

Table 1 Frequency and Percentage of Errors

\begin{tabular}{|l|c|c|}
\hline Category & Number (No.) of Errors & Percentage (\%) of Errors \\
\hline Grammar & 255 & 47.8 \\
Spelling & 161 & 30.2 \\
Lexis & 117 & 22.0 \\
\hline \multicolumn{1}{|c|}{ Total } & 533 & 100.0 \\
\hline
\end{tabular}

Of the overall number of errors, the highest occurrence of error is in grammar. This is followed by errors in spelling and lexis. The type and frequency of the errors in the corpus are presented for each category in this section of the paper. For the purpose of this study, an 
asterick (*) is placed before an incorrect word. The omission of a letter or a word is indicated with $\mathrm{a}\left({ }^{\wedge}\right)$. The correct target language form is provided in parenthesis.

\subsection{Grammatical Errors}

An error in grammar involves a violation of a grammatical rule of a word class. Given that it is a grammatical error, the error is assigned under eight word classes, namely verbs (vb), articles (ar), prepositions (prep), pronouns (prn), nouns (nn), adverbs (adv), conjunctions (conj) and adjectives (adj). The errors within these word classes are classified under four error types, namely, misselections, omissions, additions and misorderings.

Table 2 gives an overview of the types and frequencies of grammatical errors.

Table 2 Grammatical Errors

\begin{tabular}{|l|c|c|c|c|c|c|c|c|c|c|}
\hline $\begin{array}{l}\text { Categories } \\
\begin{array}{l}\text { Types } \\
\text { of Errors }\end{array}\end{array}$ & Vb & Ar & Prep & Prn & Nn & Adv & Conj & Adj & $\begin{array}{l}\text { Total } \\
\text { No. of } \\
\text { Errors }\end{array}$ & $\begin{array}{l}\% \text { of } \\
\text { Errors }\end{array}$ \\
\hline 1. Misselections & 108 & 5 & 17 & 9 & 5 & 0 & 3 & 0 & 147 & 57.7 \\
2. Omissions & 17 & 37 & 14 & 4 & 0 & 0 & 0 & 0 & 72 & 28.2 \\
3. Additions & 9 & 5 & 11 & 0 & 0 & 0 & 2 & 2 & 29 & 11.4 \\
4. Misorderings & 0 & 0 & 0 & 2 & 0 & 5 & 0 & 0 & 7 & 2.7 \\
\hline Total & 134 & 47 & 42 & 15 & 5 & 5 & 5 & 2 & 255 & 100.0 \\
\hline
\end{tabular}

Table 2 shows that the highest number of grammatical errors involves misselections, followed by omissions and then, additions, with the ieast being misorderings.

\subsubsection{Misselections}

A misselection in grammar occurs when either the wrong selection within a grammatical word class is made or the wrong form of the grammatical word class is used. Out of the total number of misselections, the highest is in verbs, followed by prepositions and then pronouns. 
It is worth noting here that the percentage of verb errors is more than $50 \%$ the total number of misselections, the most common being the incorrect use of tenses. The analysis revealed the most common tense error was the use of the simple present in a past context. In fact, there was a tendency to shift to the simple present tense form of the verb when narrating a past event, thus resulting in inconsistent tense sequence within the sentence itself. The following exemplifies such an error.

1. *I'm (was) very happy when I went to India with my family.

2. The happiest moment in my life was when $I *$ have (had) my first child.

3. On Friday night, I *send (sent) him to the airport and came back late at night.

The analysis also revealed that the most frequently used tenses were the simple present tense and simple past tense, and these contained the most number of errors, while the least frequently used tenses, the perfective and the progressive, contained the least. Students had very likely avoided using the tenses which they were not familiar with, thus resulting in the above phenomenon. In fact, the simple present tense and the simple past tense were used in contexts where either the perfective or the progressive should have been used. The following sentences illustrate the use of the simple past tense instead of the perfective.

1. I * studied (have studied) English for ten years already.

2. I went to visit my relative in Ipoh. She *lived (had lived/had been living) there since 1980.

Students also seem to have problems selecting the correct formations of the verb. The error that appeared to be recurrent was the incorrect use of the participle form in the perfective (have *learn), the incorrect form of the future tense (will *prepared), the incorrect form of the verb after a modal auxiliary (can *produced) and the incorrect infinitive form (to

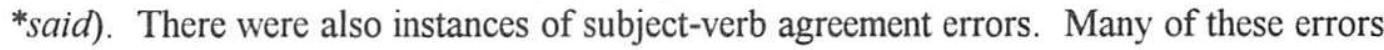
occured particularly when the subject of the sentence was singular.

\section{Everyone *are (is) friendly.}

2. She sometimes *go (goes) to bed early.

In each of the above sentences, the verb does not agree with the subject of the sentence, thus resulting in an error in subject-verb agreement. The plural verb is used instead of the singular verb. What is interesting to note here is that the failure to make the verb agree with the singular subject happens when an adverbial such as sometimes or always precedes the verb. 
The next misselection is the misselection of prepositions, although the frequency of such an error is lesser than that of verb misselections. The most noticeable error was the confusion over the choice of prepositions to indicate time and place, as illustrated in the following sentences.

1. I was very shocked *on (at) that moment.

2. We went to Taman Negara *in (on) Saturday.

3. I went to my hometown *at (in) Kedah.

4. I was posted *in (to) a Tamil school.

In sentences 1 and 2, the incorrect prepositions to indicate time are used whereas in the last two sentences, the wrong prepositions to indicate place are used. Another common feature of misselections in prepositions was the use of the wrong preposition in a verb-preposition combination where only a particular preposition could go together with the particular verb. Such errors are demonstrated below.

1. I didn't have a chance to go *for (on) a date.

2. My happiest moment was when I was pregrant *for (with) my first child.

3. I have to concentrate *in (on) my studies.

The third most frequent number of misselections was the misselection of a pronoun. However, the errors that occurred were too varied to make any significant conclusion. There were two instances of the use of the reflexive pronoun myself in place of the personal pronoun $I$ as in,

1. My family and *myself (I) went to Raub during the holidays.

2. ${ }^{*}$ Myself (I) did a lot of homework after that.

\subsubsection{Omissions}

An error is considered an omission when a necessary word class is omitted. The omissions that figured prominently in the data were the omissions of articles, followed by the omissions of the verb to be and then, the omissions of prepositions. Articles that were most commonly omitted were the indefinite articles, $a$ and $a n$. The placement of the indefinite article before noun complements and noun phrases seems to create difficulty for the students as seen from the high frequency of articles omitted, as in,

1. I had ^ (a) very enjoyable weekend.

2. It will be $\wedge$ (a) hectic weekend for me. 
3. He is $\wedge$ (an) educated person.

There were also instances of the indefinite article being omitted before expressions of quantity, such as in,

1. I spent $\wedge$ (a) lot of my time with my friends.

2. The children made $\wedge$ (a) lot of noise.

Students also seem to have omitted the definite article the before a noun. Examples of such omissions include the following.

1. I received a scholarship from ^ (the) government to study in University Malaya.

2. I go to ${ }^{\wedge}$ (the) library everyday.

Omissions of the are also found before superlatives used as adjectives, as in,

1. We had $\wedge$ (the) greatest time of our lives.

2. It was $\wedge$ (the) happiest moment in my life.

The next omission error was the omissions of the verb to be. What was predominant in the data was the omission of the verb to be as a main verb. This is illustrated in the following sentences.

1. Her husband ${ }^{\wedge}$ (is) also a teacher.

2. $\quad I^{\wedge}($ am) really happy to study in Universiti Malaya.

There were also some instances where the subjects failed to use the verb to be in the continuous tense construction and in the passive construction. The following shows this error.

1. My husband $\wedge$ (was) also sitting for an exam at that time.

2. After that $I^{\wedge}$ (was) transferred to Selangor.

The omission of prepositions is the next omission error. Most commonly, a preposition was omitted after intransitive verbs as in the following.

1. I started driving ^ (on) my own.

2. They asked $\wedge$ (about) my future plans.

3. It is interesting to $\operatorname{look}^{\wedge}($ at).

\subsubsection{Additions}

An error is considered an addition error when an unnecessary word class is added in a 
sentence. Additions do not contribute to a high percentage of grammatical errors as only $11.4 \%$ of the total grammatical errors are additions. Redundant word classes were found involving the redundant use of prepositions, followed closely by verbs and articles. Prepositions were found redundant in phrases which did not require the use of a preposition as in following examples.

1. I'm going for a picnic * $\underline{\text { at }}$ next week.

2. I still remember the first time I visited *to Malacca.

3. We named her * as Navithira.

4. When I entered* in the room, I saw a beautiful picture.

Redundant verbs were mainly the verb to be, especially before main verbs. In each of the following sentences, the verb to be was unnecessarily added before a main verb.

1. Before exams, we *are gather to discuss our studies.

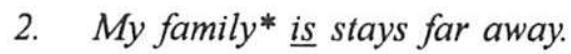

There were very few instances of redundant article usage. All five instances involved the addition of the definite article the, as in,

1. I spent my time cooking for the lunch.

2. I will go back during the Christmas.

\subsubsection{Misorderings}

A misordering error occurs when a word class is not placed in the correct order. Misordering contributes only $2.7 \%$ to the total grammatical error. An error worth noting here is the misordering of adverbs, as illustrated in the following sentences.

1. I enjoy my college life really.

2. That was the time we got to know deeply each other.

In both the sentences, the adverbs underlined were not placed in the correct order. In sentence 1, the adverb really should have been placed after the main verb enjoy, whilst in sentence 2, the adverb deeply should have been placed at the end of the sentence. These errors were committed because of the failure to realise the correct position of the adverbs.

\subsection{Spelling Errors}

An error in spelling occurs when a word is misspelled. Spelling errors are divided into two 
sub-categories, namely errors involving vowels and errors involving consonants. These errors are divided into 4 error types, namely misselections, omissions, additions and misorderings. Table 3 gives an overview of the types and frequencies of spelling errors.

Table 3 Spelling Errors

\begin{tabular}{|l|c|c|c|c|}
\hline $\begin{array}{l}\text { Types } \\
\text { of Errors }\end{array}$ & Vowels & Consonants & $\begin{array}{c}\text { Total } \\
\text { No. of } \\
\text { Errors }\end{array}$ & $\begin{array}{c}\text { \%o of } \\
\text { Errors }\end{array}$ \\
\hline 1. Misselections & 41 & 22 & 63 & 39.1 \\
2. Omissions & 35 & 26 & 61 & 37.9 \\
4. Additions & 13 & 19 & 32 & 19.9 \\
\hline & 4 & 1 & 5 & 3.1 \\
\hline
\end{tabular}

Table 3 shows that the highest number of spelling errors involves misselections, followed closely by omissions and then additions. There are very few errors involving misorderings. There are more vowel errors compared to consonant errors.

\subsubsection{Vowel Errors}

A vowel error occurs when one or more vowels in a word are misselected, omitted, added or misordered. A closer examination of Table 3 shows that the most frequent type of vowel error is misselections, followed by omissions and then additions. Misorderings constitute the least frequent error. The types of vowel errors are presented in Table 4. Some examples of misspelled words found in the data are also provided. 
An Overview of Selected Errors

Table 4 Types of Vowel Errors

\begin{tabular}{|c|c|}
\hline $\begin{array}{l}\text { Types of Vowel } \\
\text { Errors }\end{array}$ & Misspelled words \\
\hline $\begin{array}{l}\text { 1. Misselections } \\
a \text { instead of } e \\
a \text { instead of } o \\
e \text { instead of } a \\
i \text { instead of } y \\
i \text { instead of } e \\
o \text { instead of } a \\
u \text { instead of } o\end{array}$ & $\begin{array}{l}\text { collage, challange, prograssive, aspecially, avarage, } \\
\text { tolarate, vary, independant, than } \\
\text { econamically } \\
\text { gether, bechelor, grammer } \\
\text { activiti } \\
\text { Inglish } \\
\text { becouse, secondory } \\
\text { opp } \underline{\text { urtunity }}\end{array}$ \\
\hline $\begin{array}{l}\text { 2. Omissions } \\
\qquad \begin{array}{c}a \\
e \\
i\end{array}\end{array}$ & 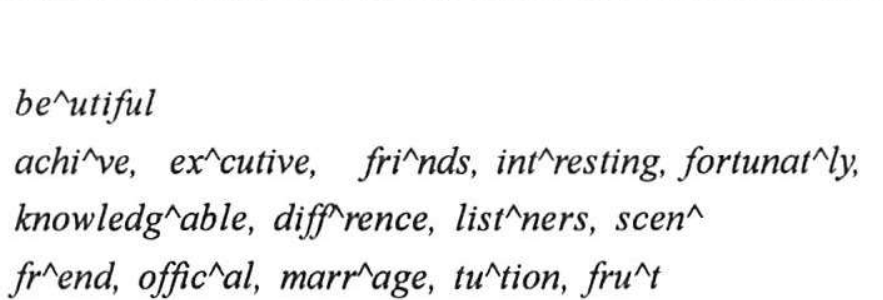 \\
\hline $\begin{array}{l}\text { 3. Additions } \\
\qquad \begin{array}{r}e \\
i \\
a\end{array}\end{array}$ & $\begin{array}{l}\text { probleum } \\
\text { happiy } \\
\text { speacially. }\end{array}$ \\
\hline $\begin{array}{l}\text { 4. Misorderings } \\
\qquad i \text { and } e\end{array}$ & recieved, studeis, thier \\
\hline
\end{tabular}

From Table 4, it can be observed that misselection type of vowel errors reflect faulty realization of sound-letter relationship. There are also errors which involve homophones, where students were confused by another word with the same pronunciation but which reflects a different meaning or syntactic function as in vary for very, and than for then. Omission errors occur as a result of omitting a vowel which the students apparently think does not contribute to the pronunciation of the word. Misspelled words which are the result of additions of a vowel show 
that students must have overgeneralised and added a vowel in the position where they think a vowel is required. There are also instances of misorderings of the vowel. This particularly involves the order of the vowels $i$ and $e$. Students who commit these errors seem to be confused about the positioning of these vowels in received, studies and their.

\subsubsection{Consonant Errors}

A consonant error occurs when one or more consonants in a word are misselected, omitted, added or misordered. A close examination of Table 3 shows that most of the consonant errors found in the data were omissions, followed by misselections and additions. Misorderings constitute the least frequent error. The types of consonant errors are listed in Table 5. Some examples of misspelled words as they appear in the corpus are also provided.

Table 5 Types of Consonant Errors

\begin{tabular}{|c|c|}
\hline $\begin{array}{c}\text { Types of Vowel } \\
\text { Errors }\end{array}$ & Misspelled words \\
\hline $\begin{array}{l}\text { 1. Misselections } \\
d \text { instead of } i \\
f \text { instead of } v e \\
f \text { instead of } v \\
r \text { instead of } l \\
s \text { instead of } c \\
t \text { instead of } d \\
s \text { instead of } t \\
v \text { instead of } w \\
z \text { instead of } s\end{array}$ & $\begin{array}{l}\text { wand } \\
\text { improf, achief, approf } \\
\text { lifes } \\
\text { rearly } \\
\text { presense } \\
\text { undergratuate } \\
\text { rasionally } \\
\text { vitness, vander } \\
\text { buzy }\end{array}$ \\
\hline $\begin{array}{l}\text { 2. Omission } \\
\qquad \begin{array}{c}f \\
h \\
l \\
n \\
p \\
r \\
s \\
t\end{array}\end{array}$ & 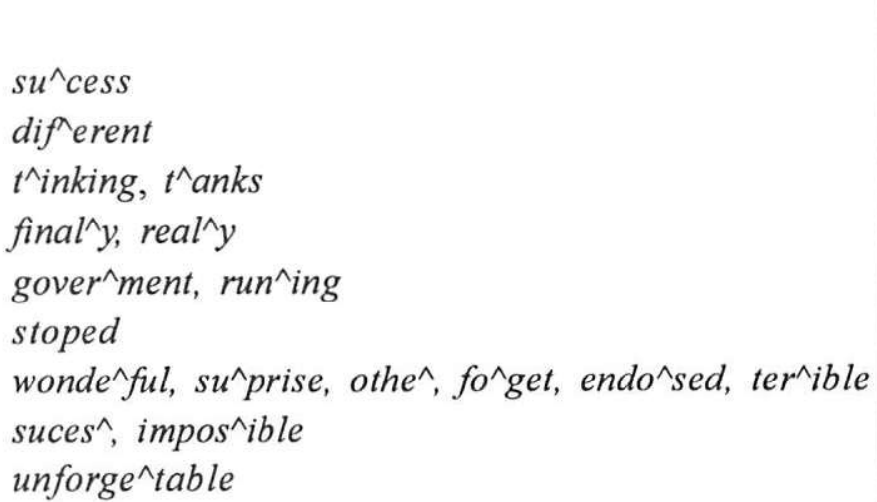 \\
\hline
\end{tabular}


An Overviow of Selected Errors

\begin{tabular}{|l|l|}
\hline $\begin{array}{c}\text { Types of Vowel } \\
\text { Errors }\end{array}$ & Misspelled words \\
\hline 3. Additions & \\
$l$ & $\begin{array}{l}\text { beautifull, joyfull, thankfull } \\
\text { carreer, althrough, throught } \\
\text { fascilities }\end{array}$ \\
$r$ & \\
\hline 4. Misorderings & assingment \\
\hline
\end{tabular}

A closer examination of Table 5 shows that misselection type consonant errors mainly reflect faulty realization of sound-letter relationships, where students have used a consonant which they think replaces the sound of a consonant in the word, thus causing a misspelling. Errors involving omissions were mainly the result of omitting a silent letter or a letter which the students think does not contribute to the sound of the word, and hence left it out. In a word where a consonant is redundant, the students seem to have overgeneralised the use of a redundant consonant which occurs at the point of affixation. Misordering errors were the result of the failure to recognise the order of consonants as they appear in a word. There was only one instance of a misordering error. The error was the incorrect position of $n$ and $g$ in assignment.

\subsection{Lexical Errors}

An error in lexis involves the use of an incorrect lexical item. Since all lexical errors in the data are misselections, the errors are classified under three main types, namely confusion of sense relations, collocational errors and confusibles. These error types have been adapted from James (1998). The following table sums up the types of lexical errors and their frequencies as found in the corpus.

Table 6 Lexical Errors

\begin{tabular}{|c|c|c|}
\hline Type of Error & Total No. of Errors & $\%$ of Errors \\
\hline 1. Confusion of sense relations & 63 & 53.8 \\
\hline 2. Collocational errors & 29 & 24.8 \\
\hline 3. Confusibles & 25 & 21.4 \\
\hline Total & 117 & 100.0 \\
\hline
\end{tabular}


Table 6 shows that more than $50 \%$ of lexical errors is the result of confusion of sense relations. Relatively fewer errors are recorded in the collocational and confusible types, respectively.

\subsubsection{Confusion of sense relations errors}

This kind of error is committed when the lexical item used is a near-synonym or an assumed synonym. The lexical item is not a true synonym and can be differentiated in terms of lexical distinctions. Errors of such nature are committed because of the confusion that arises from pairs (or more) of words that are assumed synonyms. As a result, the incorrect choice of lexical item is made. Following are some examples taken from the data.

1. We will prepare some food and *tools (equipment) for fishing in Pulau Langkawi.

2. I *finished (completed) my Teacher Training Course in 1989.

3. My friend *followed (accompanied) me to Kedah because she had never been there before.

In sentence 1 , tools is used instead of equipment; in 2, finished is used instead of completed, and in 3, followed is used instead of accompanied. Generally, tools, finished and followed are assumed by the subjects to be synonymous with equipment, completed and accompanied, respectively, and hence, can be used interchangeably. Other such examples are illustrated below:

1. I have to *manage(support) my family because I am the only one who is working.

2. My semester holiday is going to *start (begin) next week.

3. My happiest moment in life was when I *got (had) my first child.

4. Other than this *normal (usual) problem, I also face transport problems in the university.

5. I was *happy (thankful) to Murugan when I got a place in University Malaya.

6. I explained to my parents about my *idea (plan) to further my studies after Form 6

7. I always have a *talk (discussion) with my friends in our study group.

8. I couldn't believe that I had been *chosen (selected) to further my studies in U.M.

9. I also have to support my old *people(folks).

10. My happiest moment in life was when I got the *approval (offer) letter to study in UM. 
11. I am *afraid (worried) about my exams.

12. I have learnt many* subjects (lessons) in life.

\subsubsection{Collocational Errors}

Collocations are the other words any particular word normally keeps company with (James 1998). A collocational error is the result of word correspondence which is inappropriate despite the fact that the meaning intended is obvious. Errors of such nature are committed because of the ignorance of word combinations. Examples of collocational errors found in the corpus are as follows.

1. I can study hard and *add (gain) knowledge.

2. So, I have to improve my *level. (performance)

In sentence 1, add is used instead of gain, but add does not collocate with knowledge. In sentence 2, level is used instead of performance. However, improve and level are not word collocations. Other such examples are illustrated below.

1. It is mainly because I came in at the *end (late) age of 30 .

2. Next year, my son is stepping *his leg (foot) in school.

3. University life changed my *mind (thinking).

4. Next week, I plan to release my *mind (tension) by going shopping.

5. Our topics of *talking (conversations) are different now.

6. I have to *give (pay) attention in class.

7. I*did (made) a mistake when I filled in the form.

\subsubsection{Confusibles}

What is included in this category is the kinds of errors that arise as a result of confusion of some kind of similar features between pairs of words. Similarity in features of pairs of words include words which have the same word class, or have the same initial part, or end part. Because of some similar feature with a word, the student chooses a word similar to that intended, thus committing an error. The following error arose because of the confusion of similar features between matchmaking and matchmade which belong to the same word class. Here the student made the wrong choice of adjective.

\section{My marriage was a*matchmaking (matchmade) one.}

